\title{
Toward a 3D model of human brain development for studying gene/environment interactions
}

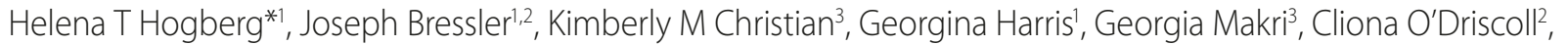 \\ David Pamies', Lena Smirnova', Zhexing Wen ${ }^{3}$ and Thomas Hartung ${ }^{1}$
}

\begin{abstract}
This project aims to establish and characterize an in vitro model of the developing human brain for the purpose of testing drugs and chemicals. To accurately assess risk, a model needs to recapitulate the complex interactions between different types of glial cells and neurons in a three-dimensional platform. Moreover, human cells are preferred over cells from rodents to eliminate cross-species differences in sensitivity to chemicals. Previously, we established conditions to culture rat primary cells as three-dimensional aggregates, which will be humanized and evaluated here with induced pluripotent stem cells (iPSCs). The use of iPSCs allows us to address gene/environment interactions as well as the potential of chemicals to interfere with epigenetic mechanisms. Additionally, iPSCs afford us the opportunity to study the effect of chemicals during very early stages of brain development. It is well recognized that assays for testing toxicity in the developing brain must consider differences in sensitivity and susceptibility that arise depending on the time of exposure. This model will reflect critical developmental processes such as proliferation, differentiation, lineage specification, migration, axonal growth, dendritic arborization and synaptogenesis, which will probably display differences in sensitivity to different types of chemicals. Functional endpoints will evaluate the complex cell-to-cell interactions that are affected in neurodevelopment through chemical perturbation, and the efficacy of drug intervention to prevent or reverse phenotypes. The model described is designed to assess developmental neurotoxicity effects on unique processes occurring during human brain development by leveraging human iPSCs from diverse genetic backgrounds, which can be differentiated into different cell types of the central nervous system. Our goal is to demonstrate the feasibility of the personalized model using iPSCs derived from individuals with neurodevelopmental disorders caused by known mutations and chromosomal aberrations. Notably, such a human brain model will be a versatile tool for more complex testing platforms and strategies as well as research into central nervous system physiology and pathology.
\end{abstract}

\section{Introduction}

This project is part of the programmed research initiated by the National Institutes of Health, the US Food and Drug Administration and the Defense Advanced Research Projects Agency to develop human-on-a-chip tools to assess the safety and efficacy of countermeasures to biological and chemical terrorism and warfare. This challenge requires not only the development of the in vitro model mimicking the human organs, as described here for the central nervous system (CNS), but also novel

\footnotetext{
*Correspondence: hhogberg@jhsph.edu

${ }^{1}$ Center for Alternatives to Animal Testing, Johns Hopkins University, Bloomberg School of Public Health, 615 N. Wolfe Street, Baltimore, MD, 21205, USA and University of Konstanz, POB 600, 78457 Konstanz, Germany

Full list of author information is available at the end of the article
}

bioengineering and quality assurance techniques. The latter will require adapting tools from Good Cell Culture Practice [1] and validation. Here, we describe the adaptation of a three-dimensional (3D) organotypic CNS model for human induced pluripotent stem cells (iPSCs).

There is a critical lack of knowledge when it comes to toxicity of drugs and other xenobiotic chemicals on the developing brain. Only very few substances have so far been confirmed to result in developmental neurotoxicity (DNT) [2], while neurodevelopmental disorders such as autism and attention-deficit hyperactivity disorder are being diagnosed at ever-increasing rates [3]. A critical constraint for routine DNT assessment of drugs and chemicals is the high cost of testing, approximately $\$ 1.4$ million per substance for the current regulatory test strategy according to the DNT guidelines $[4,5]$. But there are also scientific concerns regarding the relevance of these studies for human health effects. Testing is typically 
performed at high doses that are not relevant for human exposure scenarios, since human exposure often occurs at low doses over prolonged time periods. Nonhuman animal testing also does not reflect inter-individual differences among the human population. Moreover, the relevance of behavioral and histological data from rodents for human health has been questioned [6]. Consequently, current guidelines often do not provide sufficient information to facilitate regulatory decision-making.

\section{Modeling the complexity of the central nervous system in vitro}

3D models are far superior for recapitulating the complex directional growth and connections that underlie neurodevelopment [7]. A two-dimensional model constrains cellular morphology, preventing complex synaptic interactions. In contrast, a 3D model enables neurons and astrocytes to assume a more natural shape and extend processes to synapses and neighboring cells.

Given the importance of cell-to-cell interactions in the brain, our laboratories have begun characterizing a 3D rat primary aggregating brain cell culture model, granted by the US Food and Drug Administration (\#U01FD004230), in order to map pathways of DNT. We and others have used a variety of techniques to show the presence of all relevant cell types in these cultures [8-12]. Moreover, synaptogenesis and myelination can be observed. Consequently the model has the potential for detecting chemicals interfering with these processes; for example, by blocking the release of neurotrophic factors or interfering with cell adhesion. We are currently using emerging technologies to study neurotoxicity in these cultures $[9,10]$. For example, we have identified metabolic profiles that can distinguish compounds with different target organ toxicity (brain, kidney and liver). The DNT consensus process identified our rat aggregating culture model among the most representative models for DNT studies [13-15].

To increase the usefulness of the model, we are adapting our model for studying cells of human origin. The in vitro data from the rat and the human model can then be compared to identify possible species differences to better predict the potential for human toxicity. Such an innovative approach is expected to provide more precise information for human risk assessment, and regulatory decision-making, than the current extrapolations and predictions based on animal models. In the field of drug development, about $92 \%$ of substances fail during clinical trials due to effects in humans that were not identified in preclinical animal tests [16]. The use of human cell models is therefore crucial and has the advantage of eliminating interspecies confounds.

The use of stem cells has the potential to create new humanized models for toxicity testing. Stem cells have the capacity for self-renewal and can differentiate into all cell types of the CNS, such as neurons, astrocytes and oligodendrocytes [17]. The main sources of generating stem cells with the potential to differentiate into neural lineages are pluripotent embryonic stem cells [18-20], human umbilical cord blood-derived neural stem cells [21], multipotent somatic stem cells derived from bone marrow [22,23] or other tissues including the CNS [24] as well as iPSCs [25].

Generating stem cells from any one source will have advantages and disadvantages. In this project we chose to use iPSCs, which overcome many limitations of other sources; for example, ethical issues, limited accessibility, and restricted genetic backgrounds. In addition, iPSCs seem to be more stable, with a higher neuronal differentiation efficiency than, for example, somatic stem cells $[26,27]$. However, generating iPSCs is challenging. First, the percentage of reprogrammed cells after induction of pluripotency genes is often low. Moreover, many differentiation protocols still require further optimization because the procedure to obtain mature neurons and especially glial cells is very time consuming and the reproducibility and efficiency of differentiation can be low. In this project we are evaluating different protocols and culturing techniques to obtain a reproducible model with increased efficiency of targeted differentiation. To establish a human aggregating model, we will combine astrocytes and neurons derived from iPSCs [28,29]. Methods have been described for differentiation of iPSCs to astrocytes and different types of neurons [28,30-32]. iPSC lines from different individuals will provide a testing model with the ability to predict substance sensitivity in different genetic backgrounds. Moreover, the development of neurons and glia from iPSCs is believed to recapitulate many stages of brain development in utero [32]. Each stage of neurodevelopment is unique and displays different sensitivities to diverse xenobiotics. A DNT in vitro model should cover many of these stages.

\section{Induced pluripotent stem cell differentiation}

We have optimized protocols for differentiating human iPSCs into neural progenitor cells (NPCs) and neuronal and astroglia lineages (Figure 1). First, the generation of NPCs involves a stepwise neural differentiation protocol through embryoid body formation as previously described [25,33]. iPSCs are detached after treatment with collagenase $(1 \mathrm{mg} / \mathrm{ml})$ for 1 hour and plated onto nontreated polystyrene plates in human embryonic stem cell medium in the absence of fibroblast growth factor but in the presence of heparin with the medium exchanged daily. After 4 days in this medium the cells are switched to human NPC medium (DMEM/F12, neurobasal, heparin, N2), exchanged every 2 days. After 2 weeks in suspension cultures, embryoid bodies are collected 


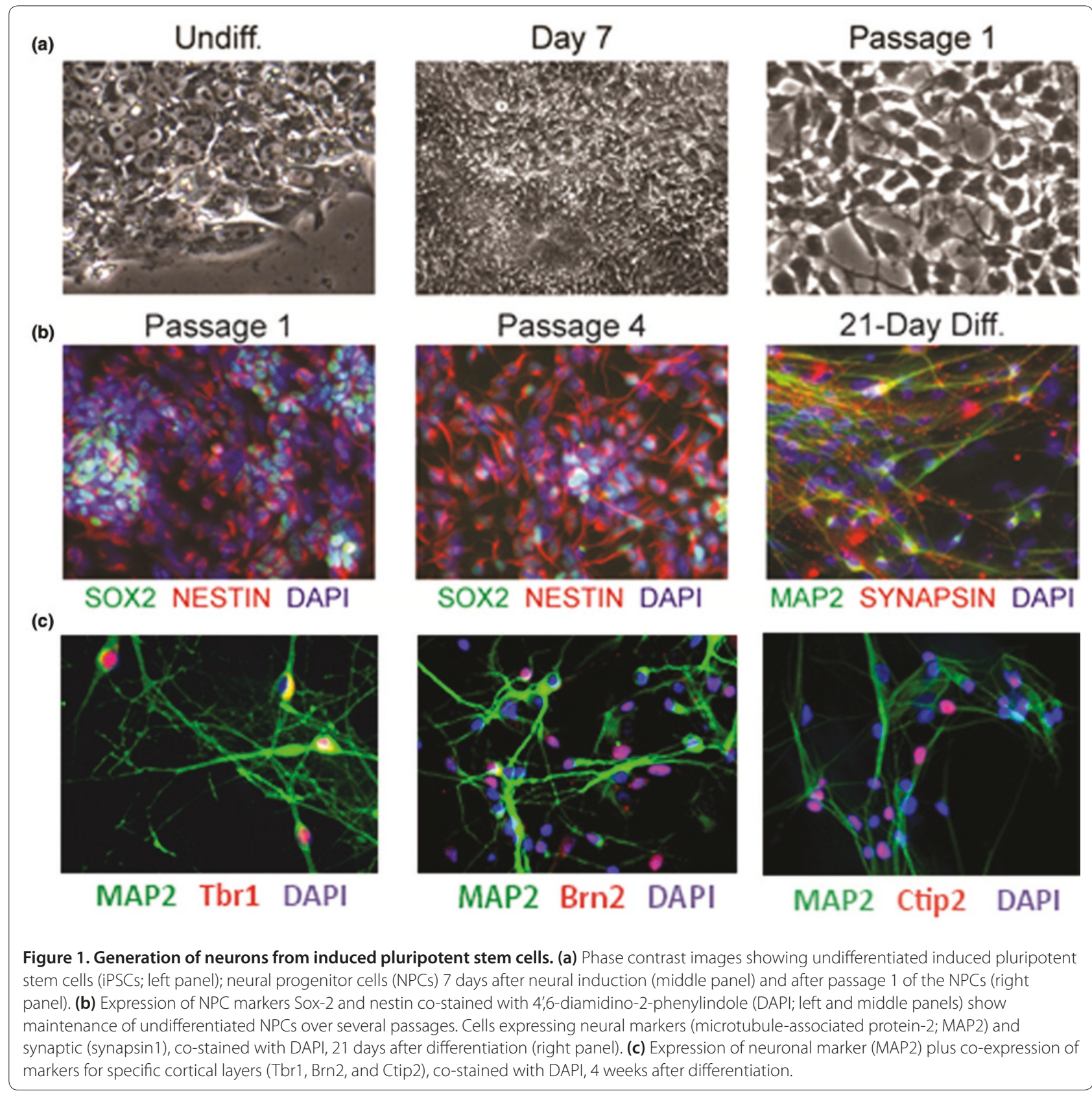

and mechanically dissociated into smaller cell clusters. These cells are plated onto poly-L-ornithine and laminincoated plates and passaged mechanically as adherent cultures (Figure 1a) in human NPC expanding medium (KnockOut DMEM/F12, Glutamax, endothelial growth factor and basic fibroblast growth factor), neural supplement and penicillin-streptomycin. To determine the purity of the culture, we stain cultures for neural progenitor markers nestin and Sox-2 (Figure 1b).

In the second protocol, for neuronal differentiation of NPCs, we plate early-passage NPCs on poly-L-ornithine and laminin-coated plates, with neuronal culture medium (neurobasal medium supplemented with $2 \mathrm{mM} \mathrm{L-}$ glutamine, B27) for 1 week to generate immature neurons (Figure 1b). Immature neurons are then cultured in neuronal medium supplemented with brain-derived neurotrophic factor $(10 \mathrm{ng} / \mathrm{ml})$ and glial cell-derived neurotrophic factor $(10 \mathrm{ng} / \mathrm{ml})$ for 4 to 8 weeks to obtain mature neurons.

In the final protocol, NPCs at a later passage are induced to differentiate into astrocytes by withdrawal of fibroblast growth factor-2 and addition of ciliary neurotrophic factor and $10 \%$ fetal bovine serum for 2 to 4 weeks. 

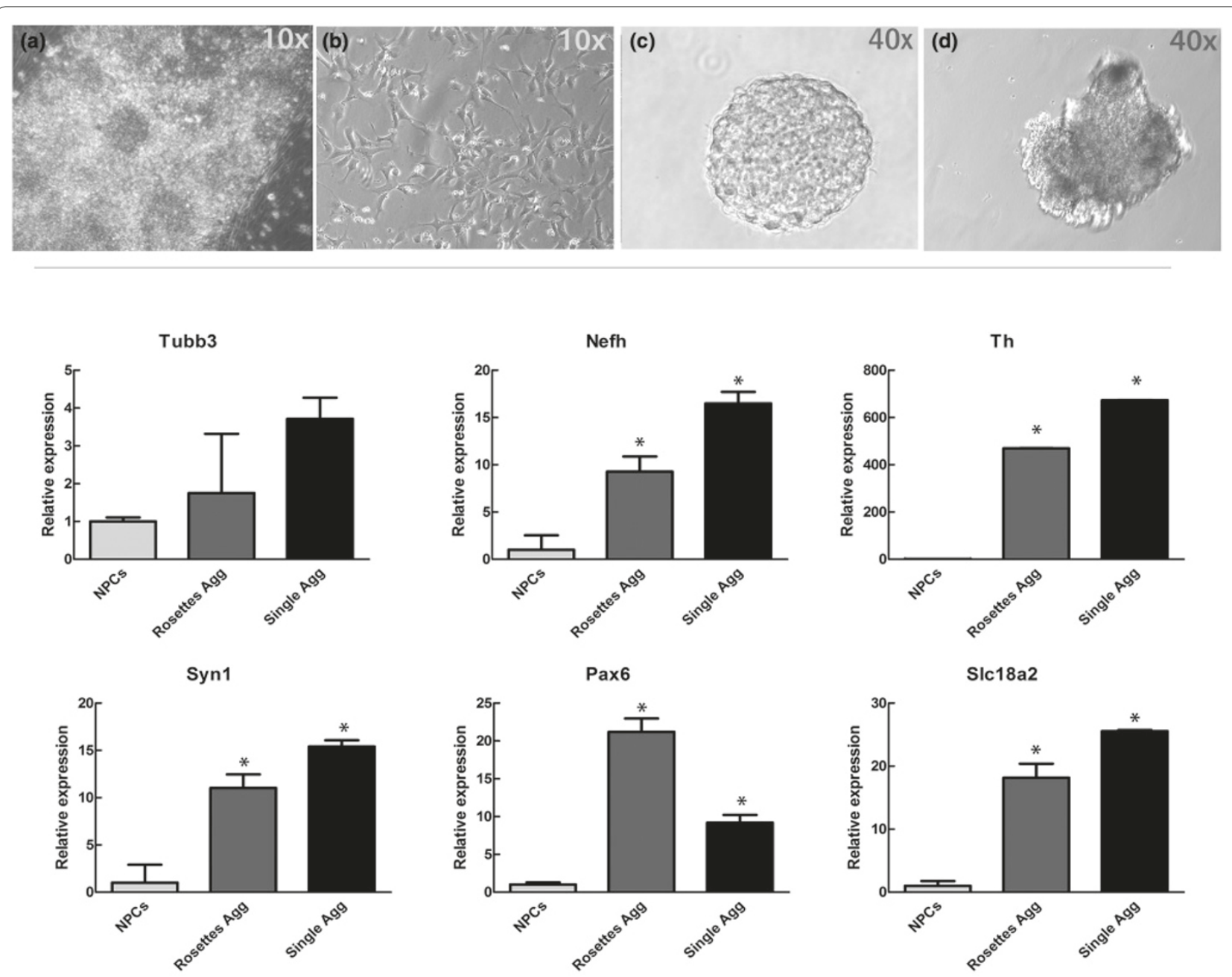

Figure 2. Three-dimensional aggregates formed during different protocols for neuro-differentiation. Phase contrast images show

(a) rosettes, (b) single human neural progenitor cells (hNPCs) in adherent cultures, (c) aggregates obtained from single hNPCs (Single Agg), and (d) three-dimensional aggregates derived from rosettes (Rosettes Agg). The lower panel shows the relative expression of different genes (neuronal markers: $\beta$-tubulin III (Tubb3), neurofilament heavy chain (Nefh), tyrosine hydroxylase (Th), synapsin 1 (Syn1), solute carrier family 18 (vesicular monoamine; Slc18a2); neural precursor marker: paired box gene 6 (Pax6)) in hNPCs and in aggregates derived from rosettes (Rosette Agg) and in aggregates obtained from single hNPCs (Single Agg) after 4 weeks in differentiating media. *Statistically different from the NPCs, $P<0.001$ Student's $t$ test).

To determine the purity of cultures, we immunostain differentiated cells for glial fibrillary acidic protein and S100 $\beta$ (astrocytic markers), DCX and microtubuleassociated protein-2ab (neuronal markers), O4 and glutathione transferase $\pi$ (oligodendrocytic markers). Extensive dendritic growth is observed by staining for microtubule-associated protein-2, and synapses are indicated with antibodies against synapsin-1 (Figure 1b). Neural progenitors can differentiate to neurons representative of cortical layers (Figure 1c) and GABAergic and glutamergic neurons as indicated by the expression of markers specific for cortical layers (Tbr1, Brn2, and Ctip2), glutamate decarboxylase, and the vesicular glutamate transporter, respectively (data not shown).

\section{Preparation of human three-dimensional neural cell cultures}

The 3D human neural model is prepared using similar techniques to those established for our 3D rat primary aggregating brain cell cultures [34]. Three approaches have so far been tested. First, cells are differentiated from NPC rosette aggregates (Figure 2a) directly in 3D (Figure $2 \mathrm{~d}$ ), inducing the differentiation using differentiation media as described above for 4 weeks. For the second approach, cells from human NPC adherent cultures (Figure 2b) are detached and plated in uncoated six-well plates with a density of $2 \times 10^{6}$ human NPCs/well (Figure 2c) for 4 weeks. In the final approach, human NPCs (Figure 3a) are differentiated two-dimensionally 


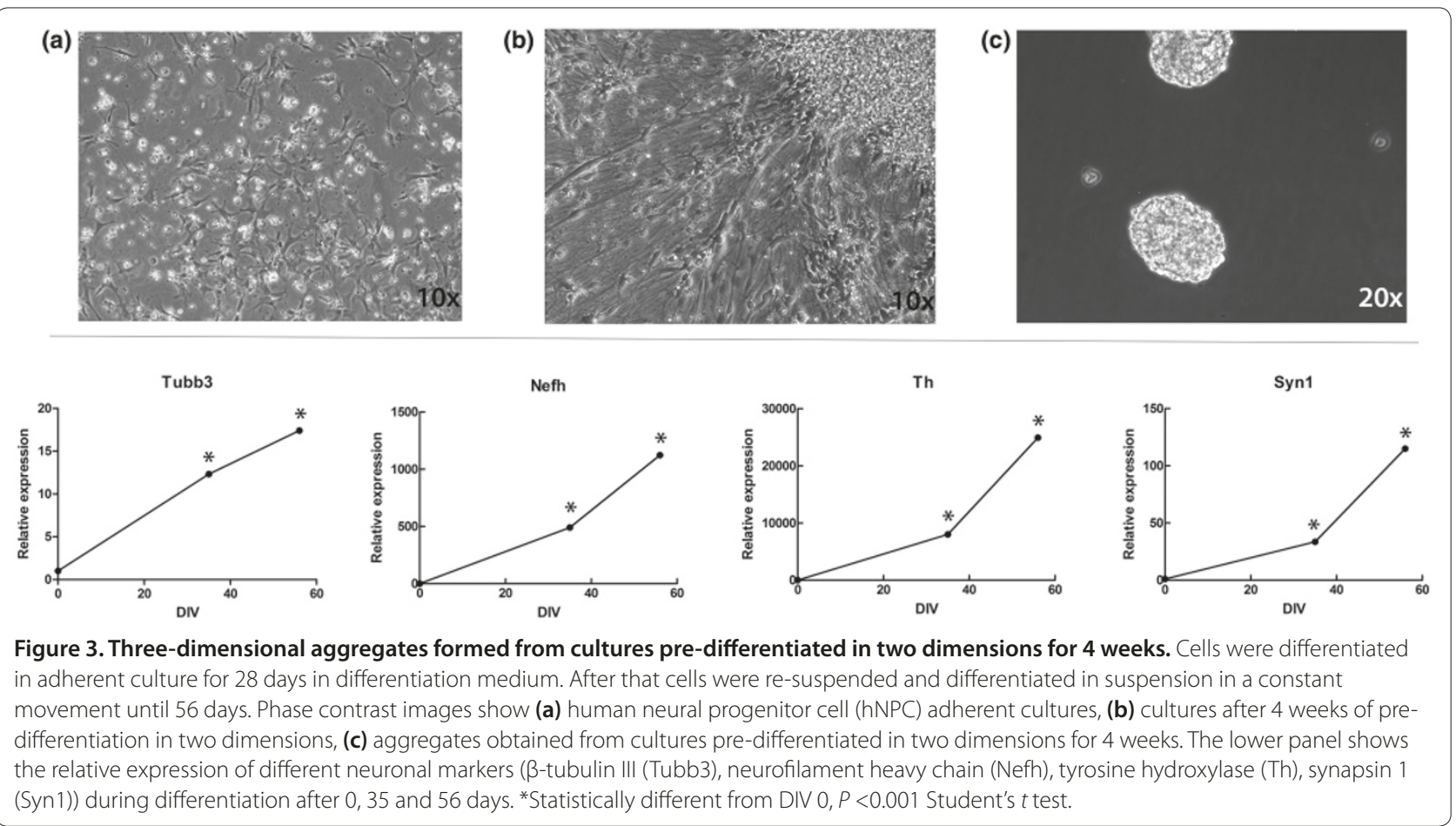

for 4 weeks (Figure 3b). After 4 weeks of differentiation, cells are detached and cultured in a 3D suspension as previously described with a density of $2 \times 10^{6}$ cells/well (Figure 3c). Cultures are maintained at $37^{\circ} \mathrm{C}$ in an atmosphere of $10 \% \mathrm{CO}_{2}$ during constant gyratory movement.

Similar to our rat brain aggregates, the $3 \mathrm{D}$ human neuronal model is characterized by (RT-)PCR and immunocytochemistry for selected markers that have been found to be involved in neuronal and glial differentiation in primary rat cultures [35,36] (Figures 2 and 3). In addition, neurotransmitter receptor activity will be assessed by measuring intracellular messengers including calcium and cAMP. Our results so far have shown higher expression of various neuronal differentiation markers in the aggregated cultures obtained from single cells than from the aggregates obtained directly from rosettes (Figure 2). Moreover, aggregates from neurons differentiated for 4 weeks in two dimensions show increased expression of different neuronal markers after the 3D formation, suggesting that the model continues to mature in 3D (Figure 3).

\section{Genetic sensitivity to xenobiotics}

A limitation to traditional animal model-based chemical and drug testing has been the inability to address the influence of (epi)genetic background and medication history on sensitivity. To investigate the impact of different genotypes of neurons derived from iPSCs on chemical sensitivity, we will generate iPSCs from patients with neurodevelopmental disorders such as Rett syndrome, tuberous sclerosis complex and Down syndrome. We chose these disorders as a point of entry because of their potential sensitivities to substances that induce oxidative stress [37]. Greater than $90 \%$ of the cases of Rett syndrome are due to methyl CpG binding protein 2 and mouse models of Rett syndrome have shown increased oxidative damage in different tissues [38]. Tuberous sclerosis complex is an autosomal dominant neurodevelopmental disorder caused by mutations in the TSC1 and TSC2 genes. In the developing child, intractable epilepsy, cognitive impairment, and autism have been reported [39]. Down syndrome is due to trisomy in chromosome 21 and is associated with impaired neurological maturation and early neurodegeneration. Several genes are expressed at higher levels due to the trisomy, which affects reactive oxygen species including superoxide dismutase.

iPSCs derived from fibroblasts of individuals with these disorders, as well as healthy individuals, will undergo neural differentiation and exposure to chemicals with predicted neurodevelopmental toxicity (Table 1). First, we will analyze the cellular response to the toxicants in the 3D neural model derived from healthy iPSC donors by measuring oxidative damage and morphological and functional endpoints such as immunohistochemistry, gene expression and calcium flux. Second, we will determine whether iPSC-derived neurons and astrocytes from patients with neurodevelopmental disorders exhibit 
Table 1. Potential developmental neurotoxicity chemicals to be tested in aggregating brain cell cultures

\begin{tabular}{|c|c|c|}
\hline Chemical & Exposure & Toxic effects and/or main mechanisms of toxicity \\
\hline Aspartame & Food additive & $\begin{array}{l}\text { Excitotoxicity mainly through activation of the NMDA-R, reduction of acetylcholine esterase activity } \\
\text { and increase in reactive oxygen species }\end{array}$ \\
\hline Bisphenol A & Plastic additive & $\begin{array}{l}\text { Endocrine disrupter at very low doses, can suppress cell proliferation, can induce apoptotic cell death } \\
\text { and produce reactive oxygen species }\end{array}$ \\
\hline Cadmium chloride & $\begin{array}{l}\text { Environmental contaminant, } \\
\text { smoking }\end{array}$ & Causes oxidative stress and affects genes involved in cell cycle regulation \\
\hline Carbaryl & Pesticide & Affects neurite outgrowth, inhibits nitric oxide synthesis and inhibits acetylcholine esterase \\
\hline Chlorpyrifos & Pesticide & $\begin{array}{l}\text { Inhibits acetylcholine esterase, induces damage to RNA and DNA synthesis, oxidative stress, astroglial } \\
\text { proliferation and cell differentiation }\end{array}$ \\
\hline Lamotrigine & Anti-convulsant drug & $\begin{array}{l}\text { Interferes with the voltage gated sodium channels and has shown teratogenic effects in some } \\
\text { studies }\end{array}$ \\
\hline Lead chloride & Environmental contaminant & $\begin{array}{l}\text { Associated with numerous adverse effects in the central nervous system, including destruction of the } \\
\text { blood-brain barrier, loss of neurons, gliosis and oxidative stress }\end{array}$ \\
\hline Lindane & Pesticide & $\begin{array}{l}\text { Inhibits acetylcholine esterase, noradrenalin uptake, GABA neurotransmission and blocks glycine } \\
\text { receptors }\end{array}$ \\
\hline Maneb & Pesticide & $\begin{array}{l}\text { Inhibits GABA synthesis, causes loss of dopaminergic and GABAergic neurons, decreases ATP levels } \\
\text { and causes oxidative stress }\end{array}$ \\
\hline Trichloroethylene & Environmental contaminant & $\begin{array}{l}\text { Associated with adverse effects in the central nervous system, induces loss of dopaminergic neurons } \\
\text { and oxidative stress }\end{array}$ \\
\hline Valproic acid & Antiepileptic drug & Recognized as a teratogenic compound, modifies the release of GABA \\
\hline
\end{tabular}

dysfunctional developmental processes as predicted by disease-relevant mutations. Finally, we will examine whether these genetic mutations increase sensitivity to a selection of DNT chemicals, presented in Table 1.

Development of such a 3D human brain model will represent a versatile tool for more complex testing platforms and strategies as well as research into CNS physiology and pathology. However, several challenges have to be considered. Differentiation and culturing protocols need to be optimized to generate reproducible models consisting of the same cell types. In this project, three different protocols are evaluated to generate the most promising 3D neuronal model. Differentiation of the NPCs as monolayer cultures before culturing in 3D will allow for better control over the cell fate of the progenitors upon aggregation. However, this approach may not be able to capture the early neurodevelopmental window, a sensitive stage of development that is of high importance. Similar challenges will probably be faced for the disease model. One cannot guarantee that iPSCderived cells from a disease-permissive genetic background will retain relevant epigenetic modifications or exhibit clear developmental phenotypes. Several epigenetic modifications in the donor tissue might be lost or modified by reprogramming of the cells. In addition, the differentiation efficiency of cells from different donors may vary, which will complicate the evaluation of effects after chemical exposure. Many challenges remain to be overcome, but as the iPSC field matures we will gain a better understanding of how to apply this technology to generate viable models of the human developing brain.

\section{Abbreviations}

CNS, central nervous system; 3D, three-dimensional; DMEM, Dulbecco's modified Eagle's medium; DNT, developmental neurotoxicity; iPSC, induced pluripotent stem cell; NPC, neural progenitor cell; PCR, polymerase chain reaction; $R T$, reverse transcriptase.

\section{Competing interests}

The authors declare that they have no competing interests.

\section{Authors' contributions}

All authors contributed equally.

\section{Acknowledgements}

This project is supported by the NCATS grant 'A 3D Model of Human Brain Development for Studying Gene/Environment Interactions' (1U18TR000547). Additional work by the group referred to in the article is supported by the US Food and Drug Administration grant 'DNTox-21c Identification of Pathways of Developmental Neurotoxicity for High Throughput Testing by Metabolomics' (U01FD004230). Publication costs will be funded by the Center for Alternatives to Animal Testing, Hugo Moser Institute at the Kennedy Krieger and Institute for Cell Engineering, Department of Neurology at Johns Hopkins University, Bloomberg School of Public Health and School of Medicine.

\section{Declarations}

Publication of this supplement has not been supported by sponsorship. Articles have undergone the journal's standard review process. The Editors declare that they have no competing interests.

This article has been published as part of Stem Cell Research \& Therapy Volume 4 Supplement 1, 2013: Stem cells on bioengineered microphysiological platforms for disease modeling and drug testing. The full contents of the supplement are available online at http://www.stemcellres.com/supplements/4/S1.

\section{Author details}

${ }^{1}$ Center for Alternatives to Animal Testing, Johns Hopkins University, Bloomberg School of Public Health, 615 N. Wolfe Street, Baltimore, MD 21205 , USA and University of Konstanz, POB 600, 78457 Konstanz, Germany. ${ }^{2 H u g o}$ Moser Institute at the Kennedy Krieger, Johns Hopkins University, Bloomberg School of Public Health, 707 N. Broadway, Baltimore, MD 21205, USA. ${ }^{3}$ nnstitute for Cell Engineering, Department of Neurology, Johns Hopkins University, School of Medicine, 733 N. Broadway, Baltimore, MD 21205, USA. 
Published: 20 December 2013

\section{References}

1. Coecke S, Balls M, Bowe G, Davis J, Gstraunthaler G, Hartung T, Hay R, Merten OW, Price A, Schechtman L, Stacey G, Stokes W: Guidance on Good Cell Culture Practice. A report of the Second ECVAM task force on good cell culture practice. Altern Lab Anim 2005, 33:261-287.

2. Grandjean P, Landrigan PJ: Developmental neurotoxicity of industrial chemicals. Lancet 2006, 368:2167-2178.

3. National Center on Birth Defects and Developmental Disabilities [http://www.cdc.gov/ncbddd/index.html]

4. OECD: Test No. 426: developmental neurotoxicity study. In OECD Guidelines for the Testing of Chemicals / Section 4: Health Effects. OECD; 2007.

[http://www.oecd-library.org/environment/ test-no-426-developmental-neurotoxicity-study_9789264067394-en]

5. US Environmental Protection Agency: Health Effects Guidelines OPPTS 870.6300. US EPA; 1998. [http://www.regulations. gov/\#!documentDetail:D=EPA-HQ-OPPT-2009-0156-0042]

6. Tsuji R, Crofton KM: Developmental neurotoxicity guideline study: issues with methodology, evaluation and regulation. Congeni Anom (Kyoto) 2012, 52:122-128.

7. Limongi T, Cesca F, Gentile F, Marotta R, Ruffilli R, Barberis A, Dal Maschio M, Petrini EM, Santoriello S, Benfenati F, Di Fabrizio E: Nanostructured superhydrophobic substrates trigger the development of 3D neuronal networks. Small 2013, 9:402-412

8. Eskes C, Juillerat-Jeanneret L, Leuba G, Honegger P, Monnet-Tschudi F Involvement of microglia-neuron interactions in the tumor necrosis factor-alpha release, microglial activation, and neurodegeneration induced by trimethyltin. J Neurosci Res 2003, 71:583-590.

9. van Vliet E, Morath S, Eskes C, Linge J, Rappsillber J, Honegger P, Hartung T, Coecke S: A novel in vitro metabolomics approach for neurotoxicity testing, proof of principle for methyl mercury chloride and caffeine. Neurotoxicology 2008, 29:1-12.

10. van Vliet E, Stoppini L, Balestrino M, Eskes C, Griesinger C, Sobanski T, Whelan $M$, Hartung T, Coecke S: Electrophysiological recording of re-aggregating brain cell cultures on multi-electrode arrays to detect acute neurotoxic effects. Neurotoxicology 2007, 28:1136-1146.

11. Zurich $M G$, Honegger $\mathrm{P}$ : Ochratoxin $A$ at nanomolar concentration perturbs the homeostasis of neural stem cells in highly differentiated but not in immature three-dimensional brain cell cultures. Toxicol Lett 2011, 205:203-208.

12. Zurich MG, Honegger $P$, Schilter B, Costa LG, Monnet-Tschudi F: Involvement of glial cells in the neurotoxicity of parathion and chlorpyrifos. Toxicol App/ Pharmacol 2004, 201:97-104.

13. Coecke S, Goldberg AM, Allen S, Buzanska L, Calamandrei G, Crofton K, Hareng L, Hartung T, Knaut H, Honegger P, Jacobs M, Lein P, Li A, Mundy W, Owen D, Schneider S, Silbergeld E, Reum T, Trnovec T, Monnet-Tschudi F, Bal-Price A: Workgroup report: incorporating in vitro alternative methods for developmental neurotoxicity into international hazard and risk assessment strategies. Environ Health Perspect 2007, 115:924-931.

14. Lein $P$, Locke $P$, Goldberg A: Meeting report: alternatives for developmental neurotoxicity testing. Environ Health Perspect 2007, 115:764-768.

15. Lein $P$, Silbergeld E, Locke $P$, Goldberg AM: In vitro and other alternative approaches to developmental neurotoxicity testing (DNT). Environ Toxicol Pharmacol 2005, 19:735-744

16. Challenge and Opportunity on the Critical Path to New Medical Products [http://www.fda.gov/ScienceResearch/SpecialTopics/CriticalPathlnitiative/ CriticalPathOpportunitiesReports/ucm077262.htm]

17. Zhang SC, Wernig M, Duncan ID, Brustle O, Thomson JA: In vitro differentiation of transplantable neural precursors from human embryonic stem cells. Nat Biotechnol 2001, 19:1129-1133.

18. Moors M, Rockel TD, Abel J, Cline JE, Gassmann K, Schreiber T, Schuwald J, Weinmann N, Fritsche E: Human neurospheres as three-dimensional cellular systems for developmental neurotoxicity testing. Environ Health Perspect 2009, 117:1131-1138.

19. Stummann TC, Hareng L, Bremer S: Hazard assessment of methylmercury toxicity to neuronal induction in embryogenesis using human embryonic stem cells. Toxicology 2009, 257:117-126.

20. Yla-Outinen L, Heikkila J, Skottman H, Suuronen R, Aanismaa R, Narkilahti S: Human cell-based micro electrode array platform for studying neurotoxicity. Front Neuroeng 2010, 3 .
21. Buzanska L, Sypecka J, Nerini-Molteni S, Compagnoni A, Hogberg HT, de Torchio R, Domanska-Janik K, Zimmer J, Coecke S: A human stem cell-based model for identifying adverse effects of organic and inorganic chemicals on the developing nervous system. Stem Cells 2009, 27:2591-2601.

22. Alexanian AR: An efficient method for generation of neural-like cells from adult human bone marrow-derived mesenchymal stem cells. Regen Med 2010, 5:891-900.

23. Hung SC, Cheng H, Pan CY, Tsai MJ, Kao LS, Ma HL: In vitro differentiation of size-sieved stem cells into electrically active neural cells. Stem Cells 2002, 20:522-529.

24. Ayuso-Sacido A, Roy NS, SchwartzTH, Greenfield JP, Boockvar JA: Long-term expansion of adult human brain subventricular zone precursors. Neurosurgery 2008, 62:223-229; discussion 229-231.

25. Hu BY, Zhang SC: Differentiation of spinal motor neurons from pluripotent human stem cells. Nat Protoc 2009, 4:1295-1304.

26. Caldwell MA, He X, Wilkie N, Pollack S, Marshall G, Wafford KA, Svendsen CN: Growth factors regulate the survival and fate of cells derived from human neurospheres. Nat Biotechnol 2001, 19:475-479.

27. Colombo E, Giannelli SG, Galli R, Tagliafico E, Foroni C, Tenedini E, Ferrari S, Corte G, Vescovi A, Cossu G, Broccoli V: Embryonic stem-derived versus somatic neural stem cells: a comparative analysis of their developmental potential and molecular phenotype. Stem Cells 2006, 24:825-834.

28. Emdad L, D'Souza SL, Kothari HP, Qadeer ZA, Germano IM: Efficient differentiation of human embryonic and induced pluripotent stem cells into functional astrocytes. Stem cells and development. Stem Cells Dev 2011, 21:404-410.

29. Chiang CH, Su Y, Wen Z, Yoritomo N, Ross CA, Margolis RL, Song H, Ming GL: Integration-free induced pluripotent stem cells derived from schizophrenia patients with a DISC1 mutation. Mol Psychiatry 2011, 16:358-360.

30. Yuan SH, Martin J Elia J, Flippin J Paramban RI, Hefferan MP Vidal JG, MuY Killian RL, Israel MA, Emre N, Marsala S, Marsala M, Gage FH, Goldstein LS, Carson CT: Cell-surface marker signatures for the isolation of neural stem cells, glia and neurons derived from human pluripotent stem cells. PloS One 2011, 6:e17540.

31. Liu H, Zhang SC: Specification of neuronal and glial subtypes from human pluripotent stem cells. Cell Mol Life Sci 2011, 68:3995-4008.

32. Nat R, Dechant G: Milestones of directed differentiation of mouse and human embryonic stem cells into telencephalic neurons based on neural development in vivo. Stem Cells Dev 2011, 20:947-958.

33. Wu H, Xu J, Pang ZP, Ge W, Kim KJ, Blanchi B, Chen C, Sudhof TC, Sun YE: Integrative genomic and functional analyses reveal neuronal subtype differentiation bias in human embryonic stem cell lines. Proc Natl Acad Sci USA 2007, 104:13821-13826.

34. Honegger PaM-T, F: Aggregating neural cell cultures. In Protocols for Neural Cell Cultures. 1st edition. Edited by Fedoroff S. Totowa, NJ: Humana Press; 2001:199-218.

35. Hogberg HT, Kinsner-Ovaskainen A, Coecke S, Hartung T, Bal-Price AK: mRNA expression is a relevant tool to identify developmental neurotoxicants using an in vitro approach. Toxicol Sci 2010, 113:95-115.

36. Hogberg HT, Kinsner-Ovaskainen A, Hartung T, Coecke S, Bal-Price AK: Gene expression as a sensitive endpoint to evaluate cell differentiation and maturation of the developing central nervous system in primary cultures of rat cerebellar granule cells (CGCs) exposed to pesticides. Toxicol Appl Pharmacol 2009, 235:268-286.

37. Franceschi C, Monti D, Scarfi MR, Zeni O, Temperani P, Emilia G, Sansoni P, Lio MB, Troiano L, Agnesini C, et al:: Genomic instability and aging. Studies in centenarians (successful aging) and in patients with Down's syndrome (accelerated aging). Ann N Y Acad Sci 1992, 663:4-16.

38. De Felice C, Ciccoli L, Leoncini S, Signorini C, Rossi M, Vannuccini L, Guazzi G, Latini G, Comporti M, Valacchi G, Hayek J: Systemic oxidative stress in classic Rett syndrome. Free Radic Biol Med 2009, 47:440-448.

39. van Eeghen AM, Black ME, Pulsifer MB, Kwiatkowski DJ, Thiele EA: Genotype and cognitive phenotype of patients with tuberous sclerosis complex. Eur J Hum Genet 2012, 20:510-515.

\section{doi:10.1186/scrt365}

Cite this article as: Hogberg HT et al.: Toward a 3D model of human brain development for studying gene/environment interactions. Stem Cell Research \& Therapy 2013, 4(Suppl 1):S4. 